\title{
Research on Lighting Installation Art Design in Public Space
}

\author{
Tingting Jiang ${ }^{1, *}$
}

\author{
${ }^{1}$ Shanghai Academy of Fine Arts, Shanghai University, Shanghai, China \\ *Corresponding author. Email: 578635424@qq.com
}

\begin{abstract}
With the continuous development of society and the advancement of urbanization, the role of lighting began to change from meeting the initial basic material conditions of people's lives to meeting people's spiritual needs for a higher quality of life. Lighting installation art then emerges as the time requires under the impetus of this environment, playing an indispensable role in urban public space. Lighting installation art is not only the way for creators to express their artistic perception, but also bringing multidimensional spiritual enjoyment for the viewers and participants in the public space. Through the representative art works, this article aims to elaborate the artistic value that lighting installation art develops in the public space, and discusses the design and application of various characteristics of lighting installation art in public space, so as to promote the lighting installation art in public landscape, make it a public art form that leads the public to appreciate and taste, and bring people a better artistic sensory experience.
\end{abstract}

Keywords: public space, lighting installation art, public art/landscape

\section{INTRODUCTION}

Installation art refers to an art form in which artists choose, utilize, transform and combine the materials artistically in daily life to present the concepts or artistic concepts that the artist want to express in a certain space environment, simply speaking, it is a comprehensive display art of "space + material + emotion". Lighting installation art is a form of installation art in which light is used as a medium of expression. It takes lighting as the main means of expression for designing creative works; it uses various materials as carriers and needs to combine a specific space environment to express the designer's artistic thinking and design intention with strong visual effect. It is a comprehensive exhibition art of "lighting + material + space + emotion".

The application of light in art can be traced back to the 1930s, when artists applied light bulbs to artistic creation, which is the most primitive light art. By the 1960 s or so, artists no longer just chose light bulbs as the medium of expression, but used mechanically controlled neon lights, fluorescent lights and so on. By the 1980s, artists used computer-controlled lasers, halogen lights and light-emitting diodes as expression media. By the end of the 1980s, light technology that can perceive and react to the outside world appeared, and artists began to use computer technology to control light, so that light can interact with the surrounding environment or people, thus producing interactive lighting art installations.

Lighting installation art is a new art form, its emergence and development is the inevitable result of art and technology. In the era of post-modern art development, installation art appears and is gradually accepted by people. Since the advent of laser in the 1960 s, the element of light began to appear gradually in the creation of installation art. By the development of optical fiber materials in the 1970s and the success of large LED screens, optoelectronic technology was also advancing step by step, and with the rise of smart cities and the maturity of intelligent control technology, the form of lighting installation art in public space has become more intelligent. At the same time, AR, VR, holographic projection and other technologies have been widely used, enhancing the immersive experience and emotional experience of lighting installation art in public space.

Norman Foster said, "We can create drama with the interaction of space, light and shadow". It is precisely because the spirituality of light brings infinite inspiration to artists that artists can use the characteristics of light to develop the dramatic elements of light in space to the extreme. 


\section{DESIGN AND APPLICATION OF LIGHTING INSTALLATION ART IN PUBLIC SPACE}

Urban public space refers to the city or urban agglomeration, there is an open space between the building entities, it is the public communication of urban residents and open places for holding various activities, and its purpose is to serve the general public. Urban public space is an important space for public activities, which can meet people's material and spiritual needs. Today is an era of visual culture, and urban public space art is undergoing a transformation from the traditional body, space, materials and other sculpture installation art language to the visual modeling language. In the process of transformation, lighting installation art plays an important role. The design, production and presentation of lighting installation art need to rely on the space environment, and the city's multiform public space provides a creative design space for it. At the same time, lighting installation art breaks the limitations of time and space, brings more possibilities to touch the new charm of the city, enjoy the landscape scenery, and taste culture in the city's public space.

\section{A. The flexible lighting installation art enhances the sense of public space to create artistic conception}

The diversity of light makes lighting installation art has incomparable flexibility artistic characteristic compared with other art forms, in recent years, it has become a new favorite for artists and designers at home and abroad. Their art works riches and attracts people's vision by using innovative and unique creative techniques and colorful artistic forms of expression. It provides more sensory possibilities for the atmosphere of our public space. Let the viewer have a broader sensory experience and resonate with the works of art, so as to produce invisible communication between the works and the viewer, so that the audience can truly integrate into the works and space.

Descanso Gardens, located on 160 acres in La Pin Flintridge, La Canada Flintridge, has long been known for its camellia forest and floral display in the International Rose Garden. In November 2016, an interactive light show "Light of the Magic Forest" was held here. It combined the charming flowers and green plants with science and technology in the wonderful forest at night, which attracted many tourists to explore. Walking into the forest park, the tree-shaped devices on both sides would sense the arrival of tourists and change the color and brightness of the lights, the "door of light" guided tourists into the mysterious and beautiful night maze. "Super Pool" was composed of a number of circular lighting interactive devices placed on the lawn, when people walked on each device, it would make corresponding response to trampling, and emitted different light color changes randomly. The trees in the forest would also change different light projection effects under the touch of tourists, just like the mysterious forest in Hogwarts Academy of Magic. The one-mile-wide night space transforms the park into a fantasy forest, where a variety of interactive light installations interweave light shapes, ideas, colors, lights and shadows to create a different mood in the public space, giving visitors a new sensory experience.

At the Desert Botanical Garden in Phoenix, designers used light installation art to show visitors a magical night desert scene just like the sea world. With cactus and desert as canvas, the dynamic light of projection and music are linked to create an immersive journey in the desert botanical garden at night. Electric Desert at the Desert Botanical Garden has seven separate installations. And Cacti Synthesia is one of them, using projection and lighting to turn cacti, succulents and rock formations into a living nighttime canvas, making the garden and its unique landscape a backdrop for new and exciting audio and visual experiences. With the theme of water in Electric Desert, the cactus seems to become a coral reef, giving the audience a sense of underwater world. The green light and shadow in the work gives people a calm and comfortable feeling, which relaxes the audience's visual nerves. Green symbolizes hope and vitality, showing a beauty of life. The lighting installation art of Phoenix Desert Botanical Garden makes people change the subjective consciousness of desert which has always been barren and vast dry and lifeless into full of vitality. This kind of subversive creation of sensory artistic conception with creative environment as the theme brings a new artistic expression effect to public space.

For the lighting installation art, the light is the soul, it is one same element as the feeling of the heart. It affects the scope is the entire light illumination space scope, the expressive force and the appeal is huge, it is inseparable with the public space ideal condition construction. Because of the different characteristics of light, lighting installation art can be used to illuminate, shape and even create a sense of space according to the needs. Lighting installation art makes use of the strong flexibility and diversity of light to create a variety of art forms through the way of illumination, light and shade, and color change, which creates a rich artistic conception of shocking the soul for public space, and also conveys a rich artistic sensory experience to the viewers.

\section{B. The interactivity of lighting installation art adds vitality to public space}

Lighting installation art is the product of the industrial revolution, its development is closely related to the development of science and technology, the design creativity is not only related to light itself, but also with digital technology, interactive capture device, 
sound effect and so on. With the help of new scientific and technological means and a variety of comprehensive materials, artists let lighting installation art works not only be art works for viewing, but also an art form of interaction with people and the environment. These interactive lighting installation art works can stimulate people's enthusiasm to participate and increase the vitality of public space, whether in the commercial field or in the art field of public space.

The Spring Festival of 2018 coincided with Valentine's Day in the West, and Vientiane City of Chongqing held a New Year fireworks and lighting art exhibition of "Light, Flame Chongqing" to welcome this romantic festival. For this reason, Qianhe Technology brought "Heartbeat" and "Magic Firework", two beautiful and romantic lighting interactive installation art works. These two art works let every participant create a unique New Year memory exclusive to them. When lovers touch the device and hold hands at the same time, they can trigger the heartbeat light effect exclusively for you. In addition, above the main device, there are 160 luminous boxes, which would change with the tone of the main device, gentle blue, elegant purple, hot red, fresh green, each color represented different emotions, love spread quietly under the gradient light. This dynamic art makes the original "dead" works of art "live", showing a living image, a form of life, a very vivid dynamic beauty. This kind of work makes full use of the interactivity of lighting installation art, attracts the attention of the audience through the change of light and color, stimulates the interest and curiosity of the audience, enables the audience to participate in the art work actively, activates the festival atmosphere, and add $s$ the vitality of public space.

Lyrical expression by scenery in literary works refers to expressing the author's feelings and position by describing the scenery in reality. In art works, "feeling" is the artist's own thoughts and feelings to express, including their subjective feelings of love, hatred, happiness and sadness, or the artist presents the audience with artistic means for the things he cares about, or the author creates interesting and attractive works purely for entertainment. Therefore, the creation of lighting installation art is not simply the embodiment of sensory feelings, but also with the help of lighting installation art to create a space atmosphere as the medium, to arouse the audience's interaction and resonance through interactive interaction.

The new technology and new means of interaction used in the creation of lighting installation art works make the appearance of lighting installation art refreshing, giving the viewer a pleasant visual enjoyment and artistic experience, this interaction is two-way, the works transfer information to the audience, the audience feedback the information to the works, the works accept and analyze the audience's information, and then feedback to the audience of new information. Lighting installation integrates art and technology, interacts with people and environment in a relaxed and dynamic way, and interweaves contemporary art design with current hot spots in many public spaces, arousing people's enthusiasm for participation and adding vitality to the city at night. It also brings new artistic feelings to the audience.

\section{The emotion of lighting installation art embodies the regional culture of public space}

Kevin Lynch put forward the concept of "readability" of urban space. Urban public space as the performance window of urban history and culture and regional characteristics, it needs a simple, distinct form of expression to increase readability. Lighting installation, as a work of art design, is a contradiction and transcendence of traditional art, through its elaborate design of form, can reflect the city's traditional history, culture or regional characteristics by means of light appropriately. Lighting installation is not only an appreciative work of art, its core value is the art of expression at night, is an important art style of contemporary Chinese avant-garde art; it can create a multi-sensory artistic conception in space to express a story of emotion, to reflect the rich spiritual and cultural implications of urban regions; the art form it expressed has a strong attraction, can transmit information and enhance the readability of the city quickly.

"Gexian Village International Tourism Resort" is located in Qianshan County, Shangrao City, Jiangxi Province, backed by Gexian Mountain, a famous Taoist mountain. In May 2020, Gexian Village has opened a night tour project to the outside officially, combined with classical landscape painting to create 19 night tour viewing points, such as Yuqing Platform, Dust Gate, Qingyou Jian, Yuansheng Pool, Yueyan Xianju, Taixueyuan. It creates a Taoist fairyland scene with great visual impact at the time of the Han Dynasty. In Gexian Village Lantern Park, long street lights bright, water flows under bridge, tourists can experience ancient garden event scene, and have a feeling of crossing history which is full of ancient charm. Largescale real lighting installation art scene, moonlight, and water system, architecture reflect each other, brilliant, very visual aesthetic feeling. The design of the whole project integrates the cultural core and elements of Taoism with the lighting installation art of modern science and technology, creating a "immortal" paradise, bringing a novel experience for tourists.

Lighting installation art embodies the spirit of our country's policies one belt and one road, mountain village construction, green mountains and rivers, and promotes the development of a rural cultural characteristics and rural tourism. For cities, it is also a 
good business card display for the prosperity, economy, culture and history of cities. Because the emotion of lighting installation art, it can concentrate the historical and cultural essence of the city, and project its strong visual effect into the urban public space visually and intuitively, it also can show the cultural connotation and local conditions and customs of the location, fully express the rich spiritual of urban regionalism, and arouse people's resonance.

\section{CONCLUSION}

Lighting installation art is the medium of art and culture, occupying a very important position in urban public space. It is one of the important components of our urban landscape, and an important link between public space and human communication. The creative flexibility of lighting installation art brings rich and colorful artistic language and forms to the art work itself, and also provides more possibilities for the sensory artistic conception of public space; the interactive display of lighting installation art can quickly attract the attention of the viewers, stimulate their curiosity and enthusiasm for participation, enrich their artistic experience, and also add vitality to the public space of nightlife; the sensibility of lighting installation art can concentrate the historical and cultural essence of the city, and reflect the regional cultural connotation and local customs of the urban public space.

In the landscape design of public space, the use of lighting installation art is often the finishing touch. In essence, its creative design needs to break the fixed mode of traditional art, to achieve the perfect integration of art and technology, content and form. Generally speaking, the reasonable and effective design of lighting installation art in urban public space will help to create a diversified urban atmosphere, improve the image beauty, interest, visual art and other positive factors of urban space, it also improves the quality of people's life in the city to some extent.

\section{References}

[1] Meng Tong. Urban Public Space Design [M]. Hubei: Huazhong University of Science and Technology Press, 2012: 11-20.

[2] LI Xi. The application of aesthetic concept of Chinese landscape painting in landscape village lighting [J]. Journal of Lighting Engineering, 2016, 27 (06): 65-69.

[3] (American) Kevin Lynch. City Image. Translated by Fang Yiping and He Xiaojun. Huaxia Publishing House, 2001.

[4] Wang Siwen. The art of lighting installation in the context of contemporary art $[\mathrm{J}]$. Modern Decoration (Theory), 2016(01):231.

[5] Ren Yue.Study on the Artistic Conception Creation of Light in Installation Art [J]. Artwork Jian,2017(02):371-372.

[6] Pang Xiaoxiao.Analysis of the application of lighting media in city night lighting [J]. Low Carbon World,2017(17):263-264. 